\title{
Orientation Analysis of Ultra-fine Grained Bulk Materials Produced by Accumulative Roll-bonding (ARB) Process by the Use of EBSP Technique
}

\author{
R. Yoda*, H. Haren*, N. Tsuji**, R. Ueji***, T. Toyoda*** and Y. Minamino** \\ * Kakogawa Laboratories, Kobelco Research Institute Inc., 1 Kanazawa-cho, Kakogawa, Hyogo, 675-0137, \\ Japan. \\ ** Department of Adaptive Machine Systems, Graduate School of Engineering, Osaka University, 2-1 \\ Yamadaoka, Suita, Osaka, 565-0871, Japan. \\ *** Graduate student of Osaka University.
}

Ultra-grain refinement (mean grain size smaller than $1 \mu \mathrm{m}$ ) of structural metallic materials has been studied to improve their mechanical properties such as strength. A novel intense plastic straining process for bulk materials, named Accumulative Roll-Bonding (ARB), has been proposed and succeeded in producing ultrafine grained microstructures [1]. It was verified recently that most of the boundaries surrounding the ultra-fine grains produced by ARB are high angle ones by means of Kikuchiline analysis in a transmission electron microscope (TEM)[2-4]. However, such a TEM method has the disadvantage that large areas in the specimen cannot be measured. On the other hand, an electron backscatter diffraction pattern (EBSP) technique in scanning electron microscope (SEM) is suitable for large area measurement, while the quality of the Kikuchi-lines obtained in a conventional SEM equipped with $\mathrm{W}$ or $\mathrm{LaB}_{6}$ filament is too low to analyze because of the intense strain accumulated and/or ultrafine size of the grains in theheavily deformed materials. In this study, EBSP measurements in a field emission scanning electron microscope (FESEM) was applied to large areas in the ARB processed materials in order to evaluate boundary misorientation as well as texture in the ultra-fine grained microstructure.

The material used in this study is a Ti-added ultra low carbon interstitial free (IF) steel sheet whose chemical composition is shown in TABLE 1. The ARB was conducted at up to 5 cycles (an equivalent strain of 4.0) under the conditions the same as those reported previously [5]. The cross section perpendicular to the transverse direction (TD) of the ARB processed sheet was prepared by twin-jet electro-polishing using a $100 \mathrm{ml} \mathrm{HClO}_{4}+900 \mathrm{ml} \mathrm{CH}_{3} \mathrm{COOH}$ solution to obtain a smooth and flat surface. The EBSP measurements were carried out using an Orientation Imaging Microscopy (OIM) system made by TexSEM Laboratories Inc., which was attached to an FESEM (FEI XL30S-FEG). The FESEM was operated at $15 \mathrm{kV}$. The

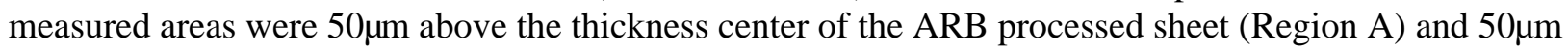
below the top surface of it (Region B). Each scan covered an area of $10 \times 50 \mu \mathrm{m}$ with a step size of 50nm, resulting in about 230,000 measurements for each.

The image quality maps for the two measured regions are shown in FIG.1. Using the FESEM/EBSP system makes it possible to obtain high quality patterns from the whole measured area even in the ARB processed specimen severely strained up to a strain of 4 . Although the measurement in a conventional SEM equipped with $\mathrm{LaB}_{6}$ filament was also tried, Kikuchi-lines sound enough to be analyzed were not obtained. These maps also show that both Regions $\mathrm{A}$ and $\mathrm{B}$ have elongated ultra-fine grained microstructure. The OIM images shown in FIG. 2 (a), (b) and (c) represent the crystal orientations parallel to the normal direction (ND) and the rolling direction (RD) of the sheet, together with the boundary misorientations for a part of Region A, respectively. The OIM images shown in FIG.3 are the same ones for a part of Region B. The boundary misorientation maps show that almost all the ultra- fine grains have high angle boundaries whose misorientations are greater than 15 degrees. These results prove that the ultrafine grains obtained by ARB ae not subgrains but "grains". The crystal orientation maps indicate that two regions have different textures, that is, the rolling-texture of $\mathrm{RD} / /<110>$ in Region A near the thickness center, while the shear-texture of 
$\mathrm{ND} / /<110>$ in Region B near the surface. This difference most likely reflects the distribution of shear strain in the ARB processed sheet reported by Lee et al. [6] recently. However, these textures are not so strong. In summary, the orientation analysis of the ultra-fine grained microstructure in large areas has succeeded by adopting the FESEM/EBSP technique.

References

[1] Y.Saito, H.Utsunomiya, N.Tsuji and T.Sakai, Acta Mater., 47 (1999), 579.

[2] N.Tsuji, R.Ueji and Y.Saito, Materia Japan, 39 (2000), 961.

[3] Y.Ito, N.Tsuji, Y.Saito, H.Utsunomiya and T.Sakai, J. Jpn. Inst. Metals, 64 (2000), 429.

[4] N.Tsuji, Y.Saito, H.Utsunomiya and T.Sakai, "Ultrafine Grained Materials”, TMS (2000), 207.

[5] N.Tsuji, Y.Saito, H.Utsunomiya and S.Tanigawa, Scripta Mater., 40 (1999), 795.

[6] S.H.Lee, Y.Saito, N.Tsuji, H.Utsunomiya and T.Sakai, Scripta Mater., 46 (2002), 281.

TABLE 1. Chemical composition of the IF steel (mass\%).

\begin{tabular}{|c|c|c|c|c|c|c|c|c|}
\hline $\mathrm{C}$ & $\mathrm{Si}$ & $\mathrm{Mn}$ & $\mathrm{P}$ & $\mathrm{S}$ & $\mathrm{Ti}$ & B & sol. Al & $\mathrm{Fe}$ \\
\hline 0.0031 & $<0.01$ & 0.15 & 0.010 & 0.005 & 0.049 & $<0.0001$ & 0.054 & bal. \\
\hline (a) & $\frac{15}{5}$ & $\frac{5}{5}$ & & & & & $\square$ & $\begin{array}{l}5 \\
\text { rees } \leq \theta \\
\text { 5degrees }\end{array}$ \\
\hline
\end{tabular}

FIG. 2. OIM maps for a part of Region A (center). (a) crystal orientation map showing ND orientations, (b) crystal orientation map showing RD orientations and (c) boundary misorientation.

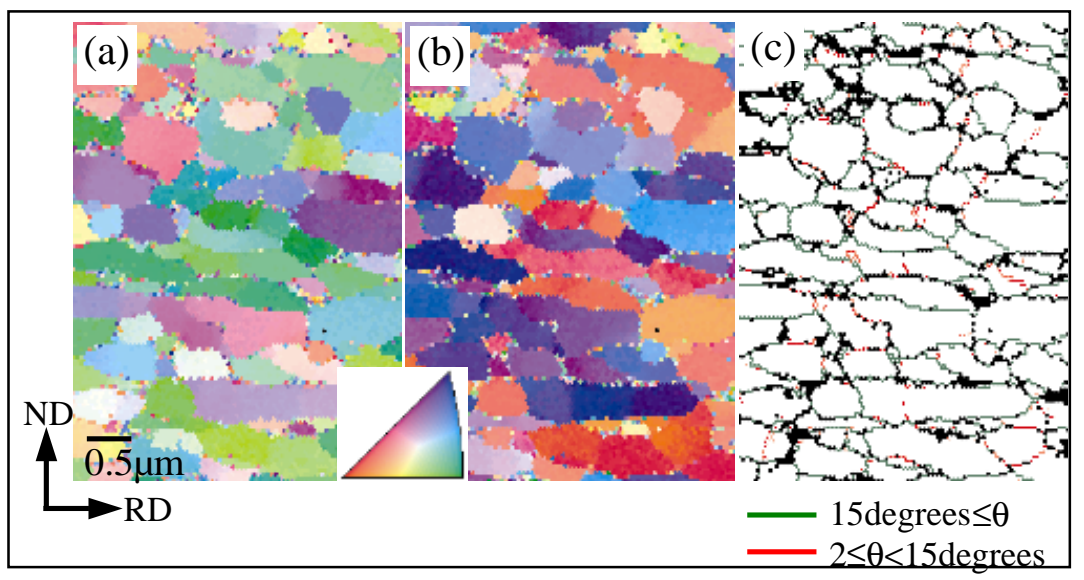

FIG. 3. OIM maps for a part of Region B (surface). (a) crystal FIG. 1. Image quality maps for

(a) Region A (center) and (b) Region B (surface). orientation map showing ND orientations, (b) crystal orientation map showing RD orientations and (c) boundary misorientation. 